\title{
Synthesis and Characterization of Cellulose from Green Bamboo by Chemical Treatment with Mechanical Process
}

\author{
Fui Kiew Liew, ${ }^{1,2}$ Sinin Hamdan, ${ }^{1}$ Md. Rezaur Rahman, ${ }^{1}$ Mohamad Rusop, ${ }^{3}$ \\ Josephine Chang Hui Lai, ${ }^{1}$ Md. Faruk Hossen, ${ }^{1}$ and Md. Mizanur Rahman ${ }^{1}$ \\ ${ }^{1}$ Department of Mechanical and Manufacturing Engineering, Faculty of Engineering, Universiti Malaysia Sarawak, \\ 94300 Kota Samarahan, Sarawak, Malaysia \\ ${ }^{2}$ Universiti Teknologi MARA, Kota Samarahan, Sarawak, Malaysia \\ ${ }^{3}$ Universiti Teknologi MARA, Shah Alam, Selangor, Malaysia
}

Correspondence should be addressed to Fui Kiew Liew; liewsan2004@gmail.com

Received 22 January 2015; Accepted 6 March 2015

Academic Editor: Yves Grohens

Copyright (C) 2015 Fui Kiew Liew et al. This is an open access article distributed under the Creative Commons Attribution License, which permits unrestricted use, distribution, and reproduction in any medium, provided the original work is properly cited.

\begin{abstract}
Bamboo cellulose was prepared by chemical process involving dewaxing, delignification, and mercerization process. Four samples namely, green bamboo fiber (GBF), dewaxed bamboo fiber (DBF), delignified bamboo fiber (DLBF), and cellulose fiber (CF) had been analysed. FTIR and TGA analysis confirmed the removal of hemicellulose and lignin at the end stage of the process. FTIR results reveal that the $\mathrm{D}$-cellulose $\mathrm{OH}$ group occurred at $1639 \mathrm{~cm}^{-1}$ region. SEM micrograph showed that mercerization leads to fibrillation and breakage of the fiber into smaller pieces which promote the effective surface area available for contact. Barrer, Joiyner, and Halenda $(\mathrm{BJH})$ method confirmed that the effective surface area of CF is two times larger compared to GBF. CF showed the highest activation energy compared to GBF. It indicates that CF was thermally stable.
\end{abstract}

\section{Introduction}

In recent years, many research works have been performed on the use of cellulose fibers as a reinforcing material for composites. This is mainly due to their high strength and stiffness combined with low weight and biodegradability. Application of cellulose nanofibers in polymer reinforcement is a relatively new research field [1]. Cellulose fibers are the most abundant renewable raw material for composite fabrication. According to Habibi et al. (2010), annual production of cellulose is more than $7.5 \times 10^{10}$ tons [2]. Regardless of the sources, cellulose consists of high molecular weight homopolymer of $\beta$-1,4-linked anhydro-D-glucose units. The repeat segment is a dimer of glucose called cellobiose [3].

Cellulose fibers have certain disadvantages including quality variations, moisture absorption, and poor compatibility with the hydrophobic polymer matrix. Lack of good interfacial adhesion, low melting point, and poor resistance towards moisture limit the usage of plant cellulose fiber. Therefore, pretreatment is needed to modify the fiber surface.
Chemical pretreatment limits the moisture absorption process and increases the surface roughness [4]. Among the various pretreatments available, acetylation, mercerization, peroxide, benzoylation, graft copolymerization, and bacterial cellulose treatment are the best methods for surface modification of fiber. For instance, mercerization leads to breaking down fiber bundle into smaller fibers. This treatment also effectively removes lignin and hemicellulose. Mercerization increases the number of possible reactive sites and allows for better fiber wetting [4]. As a result, mercerization had long lasting effect on the mechanical properties of fibers, mainly on fiber strength and stiffness [5].

Surface area analysis is done by BJH method, developed by Barrer, Joiyner, and Halenda. This method is widely used to obtain mesopore volume and mesopore size distribution [6]. This method determines pore area and specific pore volume by using adsorption and desorption techniques. An adsorption isotherm is obtained by measuring the amount of gas adsorbed across a wide range of relative pressures at constant temperature $(77 \mathrm{~K})$ using liquid nitrogen. Conversely, 
desorption isotherms are achieved by measuring gas removed as pressure is reduced.

In Borneo Island, bamboo is a fast-growing species and a high yield renewable resource. Bamboo is inexpensive, fastgrowing, and easily available, having comparable physical and mechanical properties to wood and can be processed by existing technologies [7]. The fast growth characteristic of bamboo is an advantage for its utilization. Asia and Oceania region is the richest bamboo producer with about $65 \%$ of total world bamboo resources which also include $80 \%$ of bamboo species in the world $[8,9]$.

The aim of this study is to focus on the preparation of cellulose fiber from green bamboo by mechanical process and chemical treatment. The product from each stage was characterized and analyzed. The effects of each preparation steps have also been carefully examined and compared to obtain optimize synthesis outcome.

\section{Materials and Methods}

2.1. Material. Bamboo fibers were used as a raw material for this study. Commercial cellulose was obtained from Sigma Aldrich Malaysia. The chemicals used to produce cellulose nanofibers were toluene (Sigma Aldrich, USA), ethanol (Sigma Aldrich), hydrogen peroxide (Qeric), acetic acid glacial (Ensure), titanium (IV) oxide (JT Baker), and sodium hydroxide (Merck KgaA). All chemicals used were of analytical grade.

\subsection{Methods}

2.2.1. Bamboo Fiber Preparation. The bamboo was obtained from the Forest Research Institute, Sarawak, Malaysia. The green bamboo culm with 1 meter length was prepared. It was then ground using a planner machine to produce chips and powders form excluding the internode. These chips and powders mixtures were put into an oven at $70^{\circ} \mathrm{C}$ for 72 hours to dry. The oven dried sample was ground and sieved using $600 \mu \mathrm{m}$ size siever. The $600 \mu \mathrm{m}$ mesh size fibers were used for the synthesis of cellulose fiber. This sample is labeled as green bamboo fiber (GBF).

\subsubsection{Preparation of Cellulose from Bamboo Fiber}

Dewaxing of Bamboo Fiber. $400 \mathrm{~mL}$ toluene and $200 \mathrm{~mL}$ ethanol were filled into a round flask to produce tolueneethanol of $2: 1$ ratio. The round flask is placed onto a heating element. A Soxhlet extractor was placed on top of the boiling flask and fixed tightly using a retort stand. $10 \mathrm{~g}$ of GBF was scooped into a membrane tube and then placed into the extraction thimble. A Liebig condenser is placed on top of the extractor and fixed tightly. The temperature of the heating element was observed using a digital thermometer and maintained at $250^{\circ} \mathrm{C}$.

The extraction process was continued until the color mixture disappears. The process was 2 hours with approximately $10-12$ cycles of extraction. The extraction thimble is taken out using a tweezer. The product is poured out into a beaker and stirred using a glass rod while adding toluene-ethanol mixture. The final product is filtered using a filter funnel with filter paper. It was distributed evenly using glass rod on a filter paper. It is then placed into an oven set at $70^{\circ} \mathrm{C}$ for drying overnight and was kept for delignification processes. The dried sample is identify as dewaxed bamboo fiber (DBF).

Delignification of Bamboo Fiber. The delignification solution was prepared using $82.3 \mathrm{~g}$ of $35 \mathrm{wt} \%$ hydrogen peroxide $\left(\mathrm{H}_{2} \mathrm{O}_{2}\right)$ and $106.2 \mathrm{~g}$ of $99.8 \mathrm{wt} \%$ acetic acid $\left(\mathrm{CH}_{3} \mathrm{COOH}\right)$ in the present of titanium (IV) oxide catalyst. $30 \mathrm{~g}$ of dry DBF sample was weighed and immersed into delignification solution in round bottom flask. The flask is placed onto the heater element and heated up to $130^{\circ} \mathrm{C}$.

After 2 hours, the heater was turned off and cooled to room temperature. The treated product was then filtered using Buchner flask and rinsed with deionized (DI) water until the $\mathrm{pH}$ level reached 7 and dried at $70^{\circ} \mathrm{C}$ for 24 hours. The dried sample was placed into a bottle and kept in a dark and cool place for alkaline treatment. The sample is identified as delignified bamboo fiber (DLBF).

Mercerization. DLBF was finally immersed into alkaline solution to dissolve the pectin and hemicelluloses. $6 \mathrm{wt} \%$ of sodium hydroxide was used to treat the DLBF in a flask at room temperature. The mixture was stirred using autoshaker at $150 \mathrm{rpm}$, heated to $80^{\circ} \mathrm{C}$ for 2 hours, and stopped after 8 hours of stirring. The mixture was rinsed continuously with DI water until the product reached $\mathrm{pH}$ 7. The treated product was then filtered using Buchner flask, rinsed with DI water until the $\mathrm{pH}$ level reached 7 , and freeze-dried at $-85^{\circ} \mathrm{C}$ for 48 hours.

2.2.3. Preparation of Cellulose by Mechanical Fibrillation. The cellulose was then ground using a shear grinder for $30 \mathrm{~min}$. This fine powder was called the cellulose fiber (CF). Figure 5 show the summary of cellulose preparation flow.

\subsubsection{Characterization of Cellulose}

Fourier Transform Infrared Spectroscopy (FTIR). The infrared spectra were obtained using a Shimazu FTIR Spectrometer model IRAFFINITY-1 CE. The spectra were taken at a resolution of $4 \mathrm{~cm}^{-1}$, with a total of 60 scans for each sample. The transmittance range of the scans was $600-4000 \mathrm{~cm}^{-1}$.

Scanning Electron Microscopy (SEM). The bamboo fiber samples were vacuum-dried for $24 \mathrm{~h}$ at $70^{\circ} \mathrm{C}$, pressed onto a carbon tape adhered to a sample holder surface, and sputtered with titanium. Imaging of each sample was done using Hitachi M-3030 scanning electron microscope. All images were taken at an accelerating voltage of $5 \mathrm{kV}$ with a magnification of 1500 time.

Barrer, Joiyner, and Halenda (BJH) Analysis. The bamboo fiber samples were dried for $24 \mathrm{~h}$ at $70^{\circ} \mathrm{C}$ and inserted into a capillary tube. Outgas duration was approximately 7 hours with final outgas temperature of $350^{\circ} \mathrm{C}$. After outgas process, the sample was analysed using Nova Quantachrome 4200e 


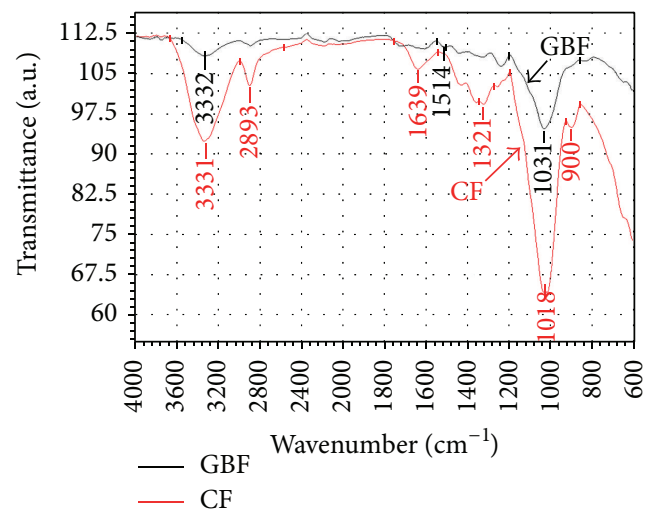

(a)

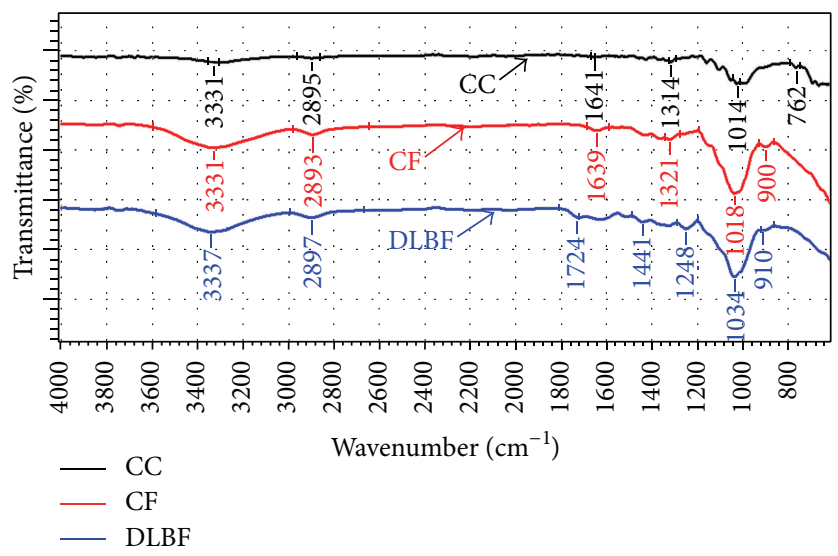

(b)

FIGURE 1: (a) FT-IR spectrum of green bamboo fiber (GBF) and cellulose fiber (CF). (b) FT-IR spectrum of commercial cellulose (CC), cellulose fiber (CF), and delignified bamboo fiber (DLBF).

automated gas sorption instrument for 1.5 hours across a wide range of relative pressures at constant temperature $(77 \mathrm{~K})$ using liquid nitrogen.

Thermogravimetric Analysis (TGA). Dynamic thermogravimetric measurements were performed using a Shimadzu DTG $60 \mathrm{H}$ instrument. The temperature programs for dynamic tests were run from ambient temperature $25^{\circ} \mathrm{C}$ to $700^{\circ} \mathrm{C}$. All measurements were made under a nitrogen flow $(20 \mathrm{~mL} / \mathrm{min})$, while keeping a constant heating rate of $10^{\circ} \mathrm{C} \mathrm{min}^{-1}$ and using an aluminum crucible with a pinhole.

\section{Results and Discussions}

3.1. FT-IR Analysis. The composition changes in GBF were investigated by FTIR spectroscopy.

Figure 1(a) shows that the peak intensity at $1514 \mathrm{~cm}^{-1}$ from the spectrum of the GBF is attributed to the $C=C$ stretching vibration in the aromatic ring of lignin. However, the cellulose fiber $(\mathrm{CF})$ did not show the $\mathrm{C}=\mathrm{C}$ stretching at that region. It indicates that lignin was well removed by chemical process [10-12].

The peak intensity band at $3331 \mathrm{~cm}^{-1}$ is attributed to O$\mathrm{H}$ stretching vibration. The bands at 2893 and $1321 \mathrm{~cm}^{-1}$ are characteristics of $\mathrm{C}-\mathrm{H}$ stretching and $-\mathrm{CH}_{2}$ bending, respectively. The peaks at 1639 and $900 \mathrm{~cm}^{-1}$ are attributed to the $\mathrm{H}-\mathrm{O}-\mathrm{H}$ stretching vibration of absorbed water in carbohydrate and the $\mathrm{C}_{1}-\mathrm{H}$ deformation vibrations of cellulose, respectively.

The peak at $1724 \mathrm{~cm}^{-1}$ in DLBF (Figure $1(\mathrm{~b})$ ) represents the ester linkage of carboxylic group of ferulic and $\mathrm{p}$ coumaric acids in hemicelluloses. The absence of this peak in CF is attributed to the removal of the hemicellulose during the alkaline treatment. This fact also indicates that hemicelluloses and lignin are removed during the chemical process and the original molecular structure of cellulose is maintained after the matrix components are removed [13].
The peak at $900 \mathrm{~cm}^{-1}$ in $\mathrm{CF}$ is connected with glycosidic $-\mathrm{C}_{1}-\mathrm{H}$ deformation, a ring vibration, and $-\mathrm{O}-\mathrm{H}$ bending. These characters imply the $\beta$-glycosidic linkages between the anhydroglucose units in cellulose. The rise of intensity peak at $1018 \mathrm{~cm}^{-1}$ confirms that the cellulose content increased due to the alkaline treatment [12].

Comparison between commercial cellulose (CC) and cellulose fiber (CF) shows that both celluloses have identical peaks. Peak at $762 \mathrm{~cm}^{-1}$ for $\mathrm{CC}$ is related to $\mathrm{C}-\mathrm{H}$ aromatic hydrogen which is identical to peak at $900 \mathrm{~cm}^{-1}$ in CF. Based on spectrums compared, it can be confirmed that cellulose fiber obtained is identical to commercial cellulose.

3.2. Scanning Electron Microscopy Analysis. Figures 2(a)2(d) showed the micrographs of GBF, DBF, DLBF, and CF respectively. Figures 2(a) and 2(b) showed that bamboo parenchyma cell was filled with starch grains and micro void. SEM micrograph showed that both GBF and DBF had no significant differences in appearance. This is due to the dewaxing process that only removes alcohol-toluene solubility content from the bamboo fiber but not the starch grains.

Figures 2(c) and 2(d) represent acetic acid-hydrogen peroxide treatment and mercerization, respectively. The surface of acetic acid-hydrogen peroxide treated fiber cell showed highly roughness with reduced microvoids from parenchyma cell. Figure 2(c) also reveals that the rough surface of cell contains fine particle which was titanium oxide catalyst and the remaining starch. However, mercerization treatment removed most of the surface particle and the surface areas were smooth without appearance of microvoids which is shown in Figure 2(d). The micrograph also confirms that mercerization leads to fibrillation and the breakage of the fiber into smaller pieces which increase the effective surface area for contact with the matrix.

3.3. Barrer, Joiyner, and Halenda (BJH) Analysis. Table 1 shows that the pore radius is identical for all four samples. 
TABLE 1: BJH surface area, pore volume, and radius.

\begin{tabular}{lcccc}
\hline Sample & $\begin{array}{c}\text { BJH surface area } \\
\left(\mathrm{m}^{2} / \mathrm{g}\right)\end{array}$ & $\begin{array}{c}\text { Total pore volume } \\
(\mathrm{cc} / \mathrm{g})\end{array}$ & $\begin{array}{c}\text { BJH-adsorption } \\
\text { pore radius }(\mathrm{nm})\end{array}$ & $\begin{array}{c}\text { BJH-desorption } \\
\text { pore radius }(\mathrm{nm})\end{array}$ \\
\hline GBF & 0.826 & $4.37 E-04$ & 1.8189 & 2.3112 \\
DBF & 1.092 & $3.67 E-04$ & 1.8210 & 2.3117 \\
DLBF & 5.430 & $3.40 E-04$ & 1.8179 & 2.3121 \\
CF & 1.755 & $5.15 E-04$ & 1.8222 & 2.3161 \\
\hline
\end{tabular}

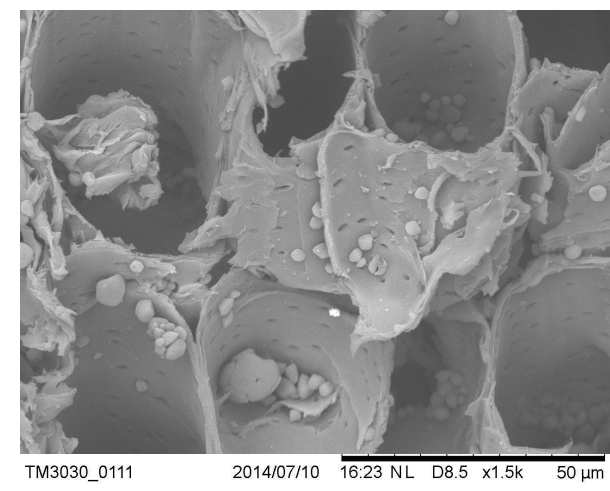

(a) GBF at $1.5 \mathrm{~K}$

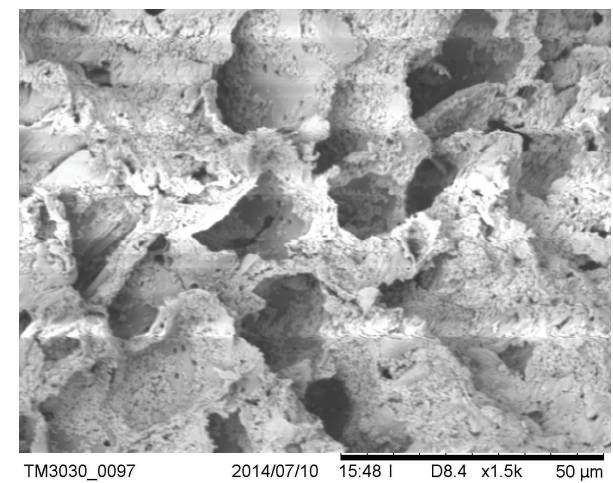

(c) DLBF at $1.5 \mathrm{~K}$

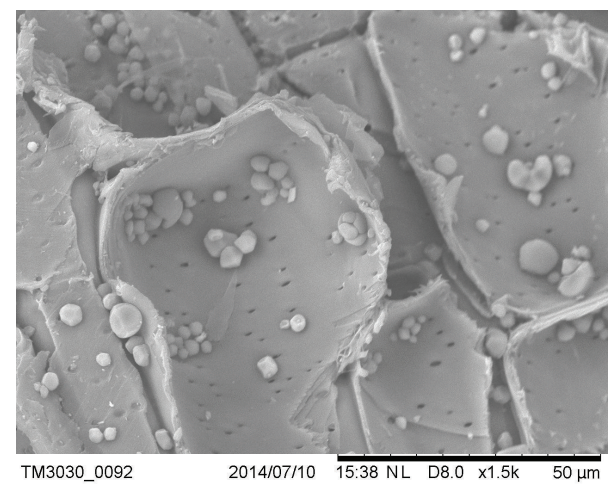

(b) DBF at $1.5 \mathrm{~K}$

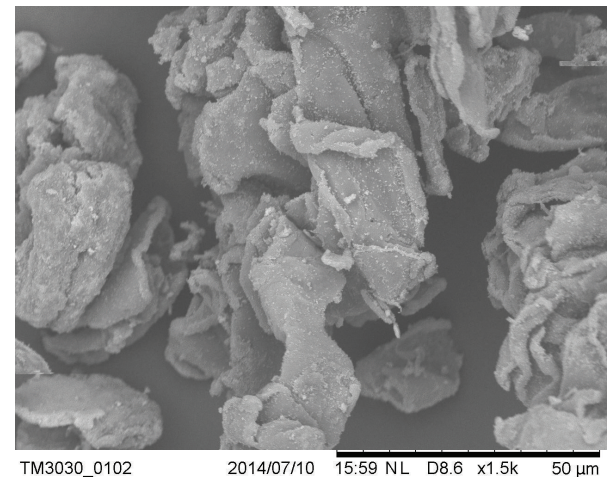

(d) $\mathrm{CF}$ at $1.5 \mathrm{~K}$

FIGURE 2: SEM micrograph of bamboo fiber under different process conditions: (a) green bamboo fiber (GBF), (b) dewaxed bamboo fiber (DBF), (c) delignified bamboo fiber (DLBF), and (d) cellulose fiber (CF).

$\mathrm{BJH}$ adsorption pore radius ranges from $1.818 \mathrm{~nm}$ to $1.822 \mathrm{~nm}$. $\mathrm{BJH}$ desorption pore radius ranges from $2.311 \mathrm{~nm}$ to $2.316 \mathrm{~nm}$. Adsorption pore radius falls in micropore regions (size < $2 \mathrm{~nm}$ ) and desorption pore radius falls in mesopore regions $(2 \mathrm{~nm}<$ size $<50 \mathrm{~nm})$ [6]. The total pore volume for three samples shows decreased trend except CF. For CF, the pore volume has a sudden increase which is due to the mechanical grinding effect on pore volume.

Figure 3 represents BJH surface area for four samples. $\mathrm{BJH}$ surface area of GBF increased after DBF and drastically decreased after DLBF. The decreased surface area of CF might be due to the mechanical grinding process that creates smaller cellulose fiber thus reduced the surface area. This result also suggested that mechanical grinding should be avoided to obtain higher BJH surface area. The final CF showed that BJH surface area is 2 times greater than the initial GBF.
3.4. Thermal Stability of Cellulose Fibers. Figure 4 showed the thermogravimetric analysis of GBF, DBF, DLBF, and $\mathrm{CF}$, respectively. The weight loss rate was obtained from the derivative thermogravimetric (DTG) data. This onset degradation temperature was defined as the intersection of tangents drawn from thermogravimetric curve, one before inflection caused by the degradation and another from the cellulose degradation step.

All bamboo fiber samples had a small weight loss in the low temperature range $\left(<100^{\circ} \mathrm{C}\right)$, corresponding to the evaporation of absorbed water $[14,15]$. The weight loss was within $12-13 \%$ of the total weight.

Green bamboo fiber (GBF) shows an earlier weight loss that started at $180^{\circ} \mathrm{C}$ and reached a dominant peak at $371^{\circ} \mathrm{C}$. The earlier weight loss in GBF was due to the decomposition of hemicellulose, lignin, and pectin. 
TABLE 2: Comparison of activation energy.

\begin{tabular}{lccccccc}
\hline Samples & $T_{i}\left({ }^{\circ} \mathrm{C}\right)^{\mathrm{a}}$ & $T_{m}\left({ }^{\circ} \mathrm{C}\right)^{\mathrm{b}}$ & $T_{f}\left({ }^{\circ} \mathrm{C}\right)^{\mathrm{c}}$ & $W_{T_{i}}(\%)^{\mathrm{d}}$ & $W_{T m}(\%)^{\mathrm{e}}$ & $W_{T f}(\%)^{\mathrm{f}}$ & \multicolumn{2}{c}{ Activation energy, } \\
$E_{a}\left(\mathrm{~J} /{ }^{\circ} \mathrm{K}\right)$
\end{tabular}

${ }^{\mathrm{a}}$ Temperature corresponding to the beginning of decomposition.

${ }^{b}$ Temperature corresponding to maximum rate of mass loss.

${ }^{\mathrm{c}}$ Temperature corresponding to the end of decomposition.

${ }^{\mathrm{d}}$ Mass loss at temperature corresponding to the beginning of decomposition.

${ }^{\mathrm{e}}$ Mass loss at temperature corresponding to the maximum rate of mass loss.

${ }^{\mathrm{f}}$ Mass loss at temperature corresponding to the end of decomposition.

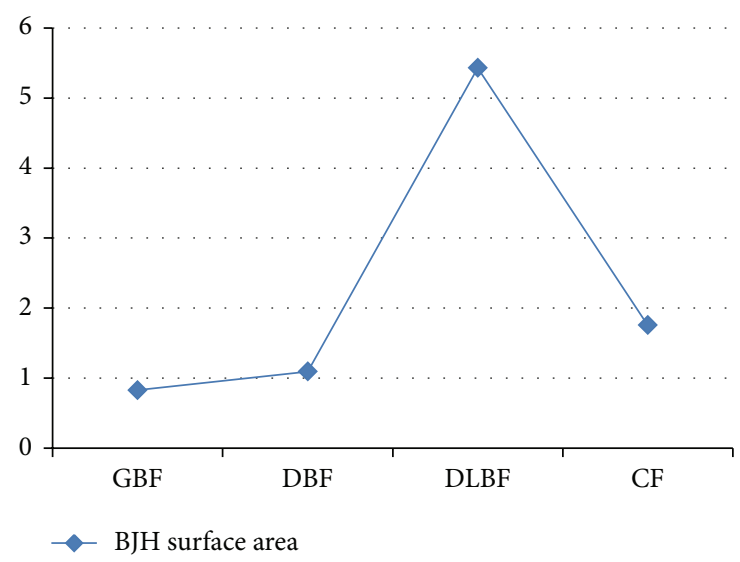

Figure 3: BJH surface area $\left(\mathrm{m}^{2} / \mathrm{g}\right)$ for all four samples.

Dewaxed bamboo fiber (DBF), delignified bamboo fiber (DLBF), and cellulose fiber (CF) showed higher decomposition temperature that started at $214-216^{\circ} \mathrm{C}$. Dewaxed bamboo fiber reached a dominant peak at $369^{\circ} \mathrm{C}$. Cellulose fiber shows a similar dominant peak at $357^{\circ} \mathrm{C}$. Delignified bamboo fiber shows highest dominant peak at $385^{\circ} \mathrm{C}$. CF sample shows the lowest weight lost due to cellulose structure which is confirmed by FTIR.

Table 2 shows the thermal stability of bamboo fiber by calculating the activation energy. The larger the activation energy is, the greater the stability is. The present calculation was based on the Broido equation and measurements from the TGA thermograms of all fiber samples [16].

Based on the analysis, CF had 1.78 times greater activation energy compared to GBF. The result proves that synthesis cellulose fiber was thermally stable compared with green bamboo fiber.

\section{Conclusions}

In this study, the cellulose was successfully synthesized using the combination of mechanical process and chemical treatment. At the end of the process, the mercerization treatment



FIGURE 4: TGA curve for thermal analysis of all four samples.

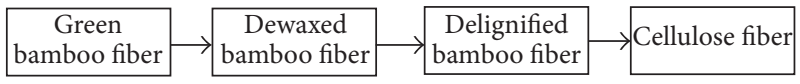

FIGURE 5: Flow diagram of preparation method.

removes lignin and hemicellulose which is confirmed by the FTIR results. The micrograph reveals that mercerization leads to fibrillation and the breakage of fiber into smaller pieces which promote the effective surface area available for contact. $\mathrm{BJH}$ method confirmed that the effective surface area of cellulose fiber is 2 times greater compared to green bamboo fiber. Cellulose fiber showed the highest activation energy. It indicates that cellulose fiber was thermally stable compared to green bamboo fiber.

\section{Conflict of Interests}

The authors declare that there is no conflict of interests regarding the publication of this paper. 


\section{Acknowledgment}

The authors would like to acknowledge the center of excellence and renewable energy (CoERE), UNIMAS, for their financial support, Grant no. CoERE/Grant/2013/06.

\section{References}

[1] I. Siró and D. Plackett, "Microfibrillated cellulose and new nanocomposite materials: a review," Cellulose, vol. 17, no. 3, pp. 459-494, 2010.

[2] Y. Habibi, L. A. Lucia, and O. J. Rojas, "Cellulose nanocrystals: chemistry, self-assembly, and applications," Chemical Reviews, vol. 110, no. 6, pp. 3479-3500, 2010.

[3] F. Chen, B. Hong, X. Guo, and G. X. Xue, "Pretreatment of bamboo powder for cellulose nanocrystalline by sulfuric acid hydrolysis," Advanced Materials Research, vol. 785-786, pp. 346353, 2013.

[4] S. Kalia, A. Dufresne, B. M. Cherian et al., "Cellulose-based bioand nanocomposites: a review," International Journal of Polymer Science, vol. 2011, Article ID 837875, 35 pages, 2011.

[5] J. Gassan and A. K. Bledzki, "Possibilities for improving the mechanical properties of jute/epoxy composites by alkali treatment of fibres," Composites Science and Technology, vol. 59, no. 9, pp. 1303-1309, 1999.

[6] G. Leofanti, M. Padovan, G. Tozzola, and B. Venturelli, "Surface area and pore texture of catalysts," Catalysis Today, vol. 41, no. 1-3, pp. 207-219, 1998.

[7] H. P. S. Abdul Khalil, I. U. H. Bhat, M. Jawaid, A. Zaidon, D. Hermawan, and Y. S. Hadi, "Bamboo fibre reinforced biocomposites: a review," Materials \& Design, vol. 42, pp. 353368, 2012.

[8] N. Bystriakova, V. Kapos, I. Lysenko, and C. M. A. Stapleton, "Distribution and conservation status of forest bamboo biodiversity in the Asia-Pacific Region," Biodiversity \& Conservation, vol. 12, no. 9, pp. 1833-1841, 2003.

[9] P. Chaowana, "Bamboo: an alternative raw material for wood and wood-based composites," Journal of Materials Science Research, vol. 2, no. 2, p. 90, 2013.

[10] S. M. L. Rosa, N. Rehman, M. I. G. de Miranda, S. M. B. Nachtigall, and C. I. D. Bica, "Chlorine-free extraction of cellulose from rice husk and whisker isolation," Carbohydrate Polymers, vol. 87, no. 2, pp. 1131-1138, 2012.

[11] F. Chang, S.-H. Lee, K. Toba, A. Nagatani, and T. Endo, "Bamboo nanofiber preparation by HCW and grinding treatment and its application for nanocomposite," Wood Science and Technology, vol. 46, no. 1-3, pp. 393-403, 2012.

[12] H. D. Nguyen, T. T. Thuy Mai, N. B. Nguyen, T. D. Dang, M. L. Phung Le, and T. T. Dang, "A novel method for preparing microfibrillated cellulose from bamboo fibers," Advances in Natural Sciences: Nanoscience and Nanotechnology, vol. 4, no. 1, Article ID 015016, 2013.

[13] W. Chen, H. Yu, and Y. Liu, "Preparation of millimeter-long cellulose I nanofibers with diameters of $30-80 \mathrm{~nm}$ from bamboo fibers," Carbohydrate Polymers, vol. 86, no. 2, pp. 453-461, 2011.

[14] J. George, K. V. Ramana, S. N. Sabapathy, J. H. Jagannath, and A. S. Bawa, "Characterization of chemically treated bacterial (Acetobacter xylinum) biopolymer: some thermo-mechanical properties," International Journal of Biological Macromolecules, vol. 37, no. 4, pp. 189-194, 2005.
[15] J. I. Morán, V. A. Alvarez, V. P. Cyras, and A. Vázquez, "Extraction of cellulose and preparation of nanocellulose from sisal fibers," Cellulose, vol. 15, no. 1, pp. 149-159, 2008.

[16] M. R. Rahman, S. Hamdan, A. S. Ahmed et al., "Thermogravimetric analysis and dynamic Young's modulus measurement of $\mathrm{N}, \mathrm{N}$-dimethylacetamide-impregnated wood polymer composites," Journal of Vinyl and Additive Technology, vol. 17, no. 3, pp. 177-183, 2011. 

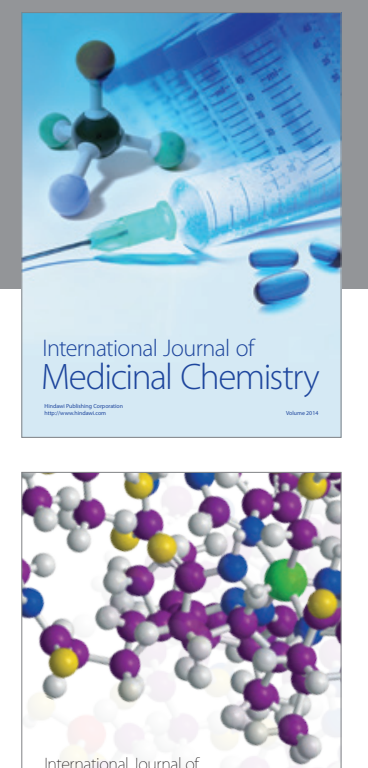

\section{Carbohydrate} Chemistry

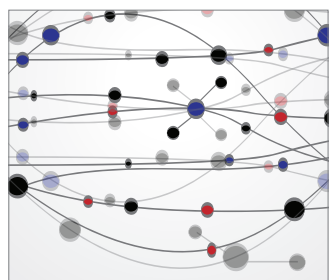

The Scientific World Journal
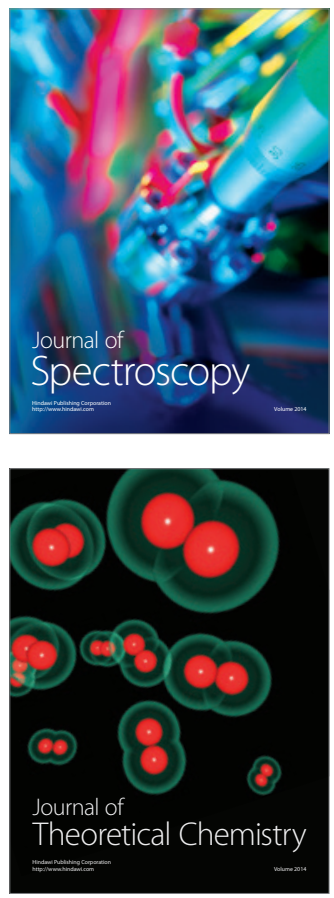
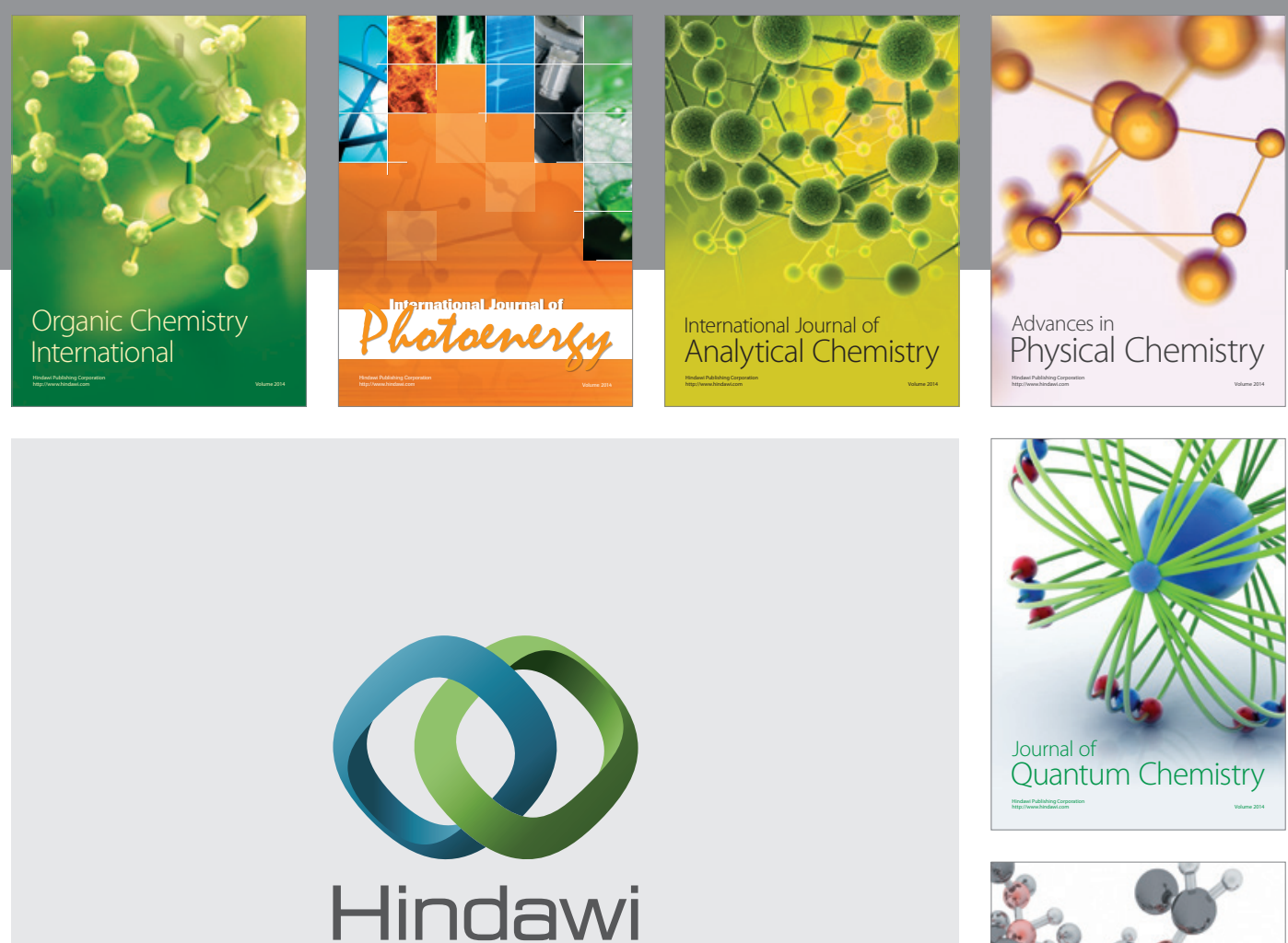

Submit your manuscripts at

http://www.hindawi.com

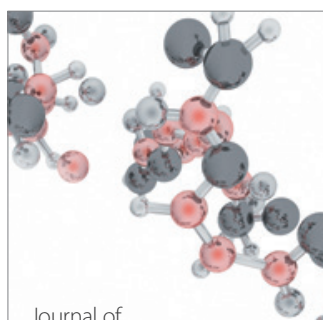

Analytical Methods

in Chemistry

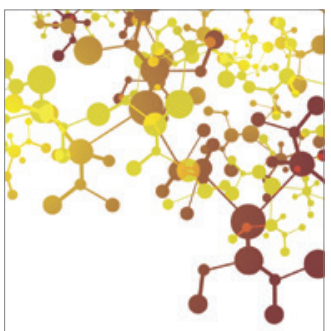

Journal of

Applied Chemistry

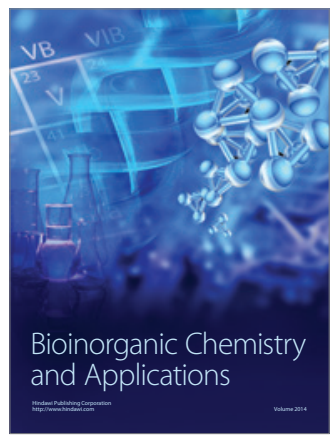

Inorganic Chemistry
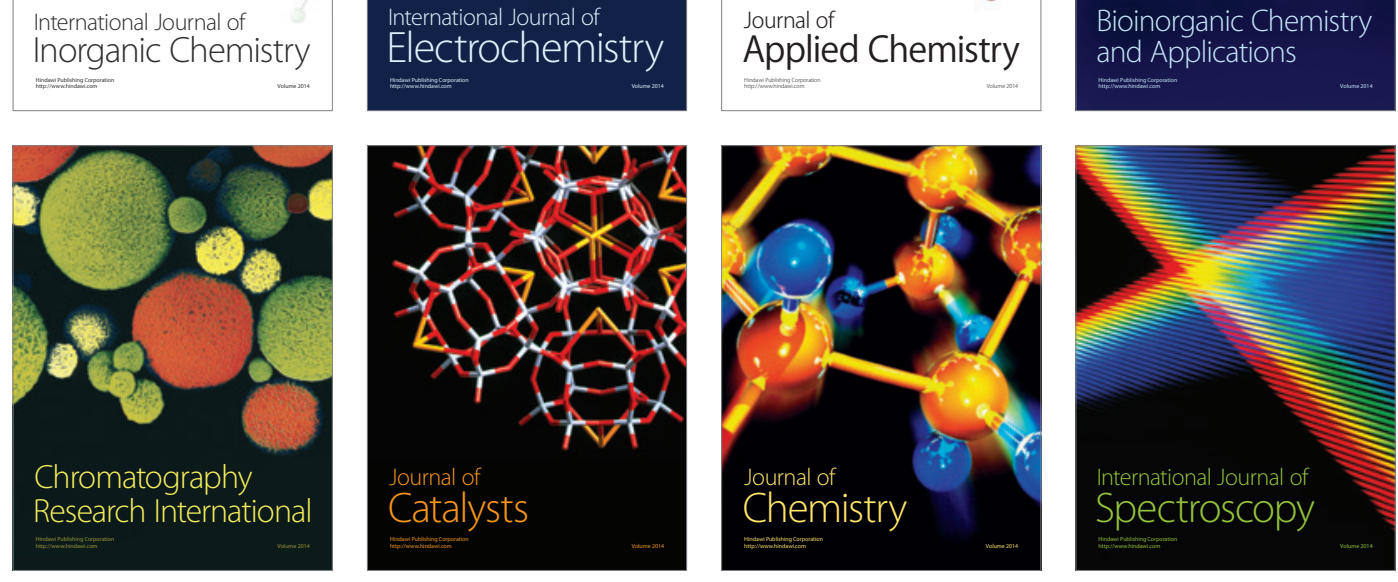